\title{
Improved survival of patients with coronary artery disease and low ejection fraction with ICD implantation versus conventional therapy in a real world survey
}

\author{
Timo Aschenbrenner ${ }^{1}$, Johannes Brockmeier ${ }^{1}$, Peter Bramlage ${ }^{2^{*}}$, Rolf Fimmers ${ }^{3}$, Alessandro Cuneo ${ }^{1,4}$,
} Stefan Hochreuther ${ }^{1}$, Claudia Zemmrich ${ }^{2}$ and Ulrich Tebbe ${ }^{1}$

\begin{abstract}
Background: Coronary artery disease (CAD) is associated with an increased risk for sudden cardiac death. Randomized controlled trials have shown that implantable cardioverter defibrillators (ICD) improve life expectancy unless they are implanted within the first days after an acute myocardial infarction and guidelines recommend their use. We aimed to validate that these results also apply to patients of a typical community hospital in Germany.

Methods: This was a retrospective analysis of patients undergoing coronary angiography in the Lippe-Detmold Hospital between 2003 and 2006. They had to have significant CAD and an ejection fraction (EF) $\leq 35 \%$ and no acute myocardial infarction within 28 days of implantation and no history of ventricular fibrillation.

Results: 213 patients were included; 70 of which received an ICD. Patients with an ICD implantation were younger $(64.8 \pm 9.9$ vs. $67.9 \pm 9.8$ years; $p=0.034)$, had single vessel CAD more frequently (22.9 vs. $11.2 \% ; p=0.025)$ and a lower EF ( $26.7 \pm 6.3$ vs. $29.1 \pm 4.6 \% ; p=0.006)$. Hospital readmissions were comparable between the ICD and the control group (68.6 vs. $72.0 \% ; p=0.602$ ). ICD therapy was associated with a considerable survival benefit compared to conventional therapy ( $\mathrm{HR} 0.52 ; 95 \% \mathrm{Cl} 0.29-0.93 ; \mathrm{p}=0.027)$ in a Cox-Proportional Hazards Regression analysis.
\end{abstract}

Conclusions: Appreciating the potential limitations of retrospective studies, we found that ICD use was associated with improved survival in patients with significant CAD and an EF $<=35 \%$ typical for a large tertiary hospital.

Keywords: Implantable cardioverter defibrillator, Cohort study, Myocardial infarction

\section{Background}

Coronary artery disease (CAD) is associated with an increased risk for angina, acute myocardial infarction (MI), reduced left ventricular ejection fraction (LVEF), congestive heart failure, and sudden cardiac death [1]. Although considerable progress has been made with respect to improving prognosis [2] approaches utilizing antiarrhythmic pharmacotherapy have been misleading [3-6], and sudden cardiac death remains a major threat to patients wellbeing. MADIT II documented that ICD use was associated with improved survival in CAD

\footnotetext{
* Correspondence: peter.bramlage@ippmed.de

${ }^{2}$ Institut für Pharmakologie und präventive Medizin, Mahlow, Germany

Full list of author information is available at the end of the article
}

patients with prior $\mathrm{MI}$ and reduced $\mathrm{LV}$ function (EF $\leq$ 30\%) [7] while DINAMIT reported no benefit with respect to overall mortality in patients with ICD implantation within days after an acute myocardial infarction [8]. ICD therapy is recommended by the recent guidelines for the primary prevention of ventricular arrhythmias and sudden cardiac death in patients with LV dysfunction due to prior MI who are at least 40d post-MI and have an LVEF $\leq 30-40 \%$, NYHA II and a good reasonable expectation of survival with a good functional status for more than 1 year (Level of Evidence A) [9]. In clinical practice, ICDs appear to reduce all cause and arrhythmic death to a similar degree as in primary prevention trials [10]. We aimed to validate the results of the aforementioned trial in clinical practice by a

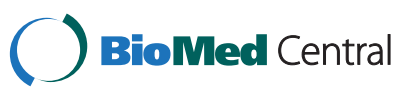


retrospective documentation of patients with ICD implantation between 2003 and 2006.

\section{Methods}

This was a retrospective analysis of patients undergoing coronary angiography in the cardiology unit of the Lippe-Detmold Hospital, a tertiary care hospital, between January $8^{\text {th }} 2003$ and December $18^{\text {th }} 2006$. Ethic committee approval as well as patient informed consent was not obtained due to the retrospective design of the study.

\section{Patients}

Patients included had undergone coronary angiography because of significant CAD and an $\mathrm{EF} \leq 35 \%$ on monoplane evaluation and had an indication for the primary prevention of ventricular arrhythmias and sudden cardiac death [9]. Exclusion criteria were acute myocardial infarction less than 28 days ago, known cancer (because of the limited life expectancy), and cardio-pulmonary resuscitation due to ventricular fibrillation.

\section{Documentation}

Follow-up data for a duration of at least 30 months were collected from hospital charts when patients were readmitted or via contact by telephone. The following variables were obtained: date of birth, gender, the presence of CAD and the number of vessels diseased, LVEF, the presence of diabetes and concomitant medication. During follow-up data on readmissions to the hospital and the reasons for referral, the adequacy of shocks and overall duration of survival were gathered.

\section{Statistics}

This data were analyzed with Aabel 20/20 data vision $3^{\circledR}$ from Gigawiz Ltd Co. Descriptive statistics were applied, based on available data and significance calculated using the two-tailed unpaired t-Test. Kaplan-Meier estimates used to compare survival and the p-value calculated by the log-rank test. Further a proportional hazards model was built considering variables displaying significant differences at baseline $(\mathrm{p}<0.05)$.

\section{Results}

\section{Patient characteristics}

A total of 213 patients (70 receiving an ICD, 143 receiving none, $15.0 \%$ female) were included into this analysis (Table 1). Patients in the ICD group were significantly younger, had single vessel CAD more frequently and a lower ejection fraction. Except for the use of statins, which was more frequent in patients receiving an ICD, pharmacotherapy was not different between groups.
Table 1 Patients characteristics

\begin{tabular}{|c|c|c|c|}
\hline & Control & ICD & $p$ \\
\hline & $(n=143)$ & $(n=70)$ & \\
\hline Age in years, mean $( \pm S D)$ & $67.9 \pm 9.8$ & $64.8 \pm 9.9$ & 0.034 \\
\hline Gender, women, n (\%) & $26(18.2 \%)$ & $6(8.6 \%)$ & 0.065 \\
\hline \multicolumn{4}{|l|}{ Coronary artery disease (CAD) } \\
\hline 1-vessel CAD, n (\%) & $16(11.2 \%)$ & 16 (22.9\%) & 0.025 \\
\hline 2-vessel CAD, n (\%) & $41(28.7)$ & $23(32.9)$ & 0.531 \\
\hline 3-vessel CAD, n (\%) & $86(60.1)$ & $31(44.3)$ & 0.029 \\
\hline $\begin{array}{l}\text { Left ventricular ejection } \\
\text { fraction (LVEF), \% }\end{array}$ & $29.1 \pm 4.6$ & $26.7 \pm 6.3$ & 0.006 \\
\hline LVEF, women, \% & $29.4 \pm 4.5$ & $28.7 \pm 7.7$ & \\
\hline LVEF, men, \% & $29.0 \pm 4.7$ & $26.5 \pm 6.1$ & \\
\hline LVEF, 1-vessel CAD, \% & $29.4 \pm 4.2$ & $26.3 \pm 7.0$ & \\
\hline LVEF, 2-vessel CAD, \% & $28.7 \pm 4.7$ & $25.2 \pm 7.1$ & \\
\hline LVEF, 3-vessel CAD, \% & $29.3 \pm 4.7$ & $28.1 \pm 5.0$ & \\
\hline Diabetes, n (\%) & $56(39.2)$ & $24(34.3)$ & 0.490 \\
\hline \multicolumn{4}{|l|}{ Pharmacotherapy, n (\%) } \\
\hline Betablockers & $132(93.0)$ & $68(97.1)$ & 0.215 \\
\hline ACE inhibitors & $110(77.5)$ & $59(84.3)$ & 0.245 \\
\hline ARBs & $19(13.4)$ & $6(8.6)$ & 0.307 \\
\hline Statins & $93(65.5)$ & $57(81.4)$ & 0.017 \\
\hline Diuretics & $125(88.0)$ & $58(82.9)$ & 0.303 \\
\hline Antiarrhythmics (Amiodarone) & $6(4.2)$ & $3(4.3)$ & 0.984 \\
\hline Anticoagulation & 51 (35.9) & $27(38.6)$ & 0.706 \\
\hline
\end{tabular}

Legend: ARB, Angiotensin II Receptor Blockers; CAD, coronary artery disease; $I C D$, implantable cardioverter defibrillator, LVEF, left ventricular ejection fraction; SD, standard deviation.

\section{Therapy}

On follow-up hospital readmissions in the ICD group were comparable to the CT group (Table 2). Reasons were rhythm disorders, ICD related reasons and a decompensation of heart failure, which was more frequent in the ICD group. In the control group there were seven late ICD implants and two patients received a cardiac resynchronization device (CRT-D). In the ICD group one device was upgraded to a CRT-D.

\section{Survival}

ICD therapy was associated with a significant survival benefit compared to conventional therapy (HR 0.52; 95\% CI 0.29-0.93; $\mathrm{p}=0.027$ ) in a Cox-Proportional Hazards Regression analysis. Curves began to diverge at 24 months of follow-up (Figure 1, Table 3). This benefit was preserved in patients with the longest follow-up of 78 months. There were a nominally larger proportion of patients with inappropriate (those not due to ventricular fibrillation) ICD shocks within the group of patients dying (21.4 vs. $5.4 \% ; \mathrm{p}=0.0896$, exact fisher test). 
Table 2 Complications after inclusion and ICD therapy

\begin{tabular}{|c|c|c|c|}
\hline \multirow[t]{2}{*}{ Complications after inclusion } & \multirow{2}{*}{$\frac{\text { Control }}{(n=143)}$} & \multirow{2}{*}{$\frac{\text { ICD }}{(n=70)}$} & \multirow[t]{2}{*}{ p } \\
\hline & & & \\
\hline Hospital Admissions, n (\%) & $103(72.0)$ & $48(68.6)$ & 0.602 \\
\hline Rhythm disorders, n (\%) & $18(12.6)$ & $12(17.1)$ & 0.369 \\
\hline Heart failure, n (\%) & $13(5.1)$ & $18(37.1)$ & $<0.001$ \\
\hline \multicolumn{4}{|l|}{ Late implants } \\
\hline Time from EF to ICD / CRT (months) & $33.1 \pm 20.7$ & $2.3 \pm 4.4$ & \\
\hline Late ICD implantation, n (\%) & $7(4.9)$ & - & \\
\hline CRT-D implantation, n (\%) & $2(1.4)$ & - & \\
\hline CRT-D upgrade, n (\%) & - & $1(1.4)$ & \\
\hline ICD therapy $(n=70)$ & $\begin{array}{l}\text { Survivor } \\
(n=56)\end{array}$ & $\begin{array}{l}\text { Death } \\
(n=14)\end{array}$ & $p$ \\
\hline ICD shock, n (\%) & $15(26.8)$ & $4(28.6)$ & 1.000 \\
\hline Inappropriate* shocks, n (\%) & $3(5.4)$ & $3(21.4)$ & 0.090 \\
\hline No ICD shocks, n (\%) & $38(67.9)$ & $9(64.3)$ & 1.000 \\
\hline
\end{tabular}

Legend: ICD, implantable cardioverter defibrillator; Time from EF to ICD, time between determination of EF (Ejection Fraction) and ICD implantation; CRT-D, cardiac resynchronization device; *as inappropiate those shocks were classified that were not due to ventricular fibrillation.

\section{Discussion}

Guideline recommendations for the primary prevention of ventricular arrhythmias and sudden cardiac death such as that of the ACC/AHA/ESC [9] rely on information derived from randomized, controlled trials. These trials have a high internal validity for the patient group actually included, but may lack such validity for a
Table 3 Outcomes of patients in our registry

\begin{tabular}{|c|c|c|}
\hline & Detmold ICD + & Detmold ICD - \\
\hline & $(n=70)$ & $(n=143)$ \\
\hline & \multicolumn{2}{|c|}{$\begin{array}{l}\text { Coronary artery disease with an } \mathrm{EF} \leq 35 \% \text {, } \\
\text { no } \mathrm{Ml} \text { within the last } 28 \text { days, without known } \\
\text { cancer or history of ventricular fibrillation }\end{array}$} \\
\hline Mean follow-up & \multicolumn{2}{|c|}{44 months } \\
\hline Total mortality & 20.0 & 37.8 \\
\hline HR Total mortality & \multicolumn{2}{|c|}{ HR $0.52(95 \% C l 0.29-0.93) ; p=0.027$} \\
\hline $\begin{array}{l}\text { Heart failure related } \\
\text { hospitalization }\end{array}$ & 25.7 & 8.3 \\
\hline
\end{tabular}

Legend: $\mathrm{HR}$, hazard ratio; $\mathrm{Cl}$, confidence interval, $\mathrm{EF}$, ejection fraction; LV, left ventricular.

substantial proportion of patients in clinical practice. Therefore we aimed to validate these trials in the patient population of our community hospital in Detmold. Overall 213 patients were retrospectively documented and prospectively evaluated for survival and appropriateness of shocks. We found that ICD use was associated with a considerable improvement of survival which was statistically significant.

\section{Study population}

Patients in the present registry were included if they had CAD with an $\mathrm{EF} \leq 35 \%$ and no MI within the last 28 days. This patient population is only partially present in most of the ICD trials [8,11-15], but has a substantial overlap with those of MADIT-II [7], which included

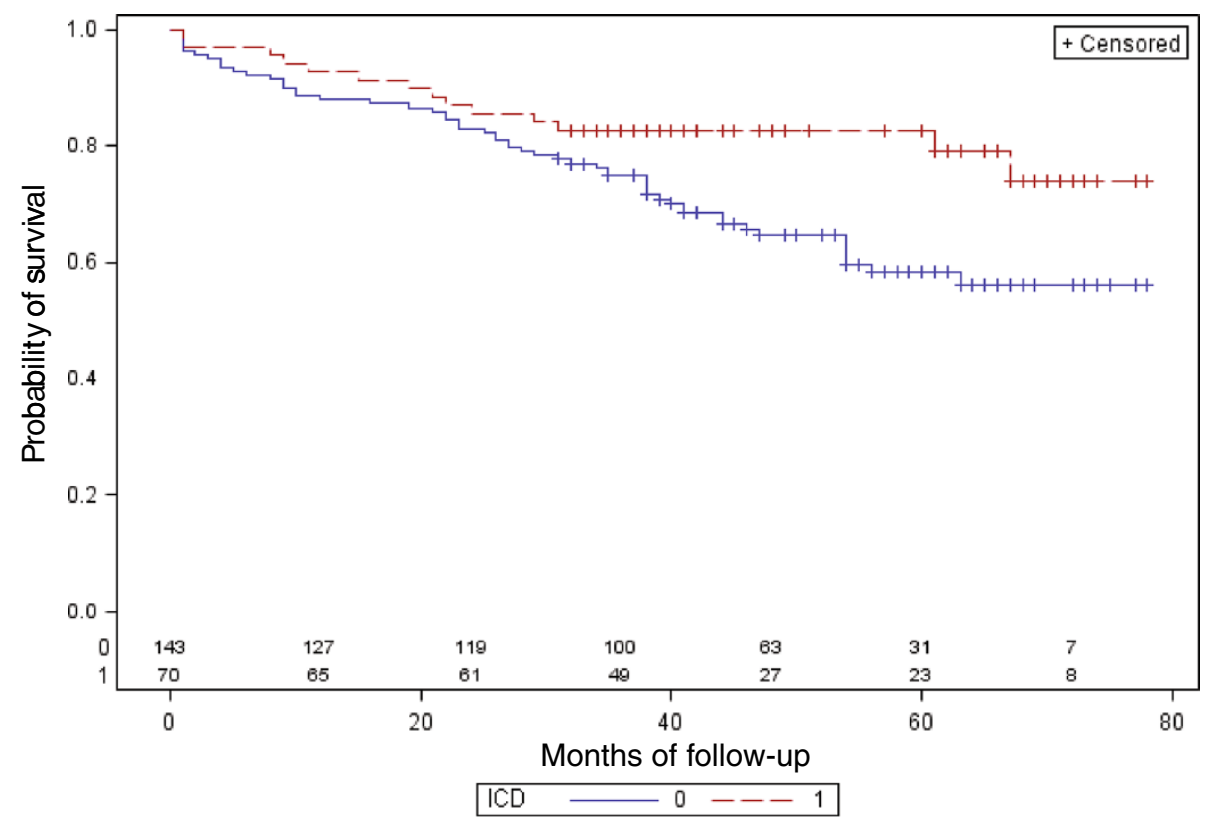

Figure 1 Probability of survival: $\mathbf{0 . 0} ; \mathbf{0 . 2} ; \mathbf{0 . 4} \mathbf{0} \mathbf{0 . 6} \mathbf{0 . 8} \mathbf{1} \mathbf{1 . 0}$ - Kaplan-Mayer overall survival in patients receiving ICD vs. conventional therapy. Legend: ICD, implantable cardioverter defirbillator. 
patients with prior MI more than 28 days ago and an EF $\leq 30 \%$. Therefore Table 4 displays clinical characteristics of patients in both MADIT-II and our observation and illustrates that while age, gender and diabetes prevalence was roughly comparable, LVEF was less reduced in our observation (because of the inclusion of patients with an EF $\leq 35$ vs. $\leq 30 \%$ ). Diuretic use was nominally less in MADIT-II (76\%) than in our observation (86\%). More patients received betablockers, ACEinhibitors and (at least for ICD patients) statins; antiarrhythmic use was substantially lower (4 vs. 15\%). This might be attributable to the fact that our patients were included between 2003 and 2006 after the publication of MADIT-II, for which patients were included between 1997 and 2001. These data illustrate that patients from recent registries such as our observation might have a differential profile to randomized, controlled trials conducted previously. With the more frequent use of optimal medical therapy patient prognosis has been so much improved that absolute risks for cardiovascular events and total mortality might differ substantially between respective patients [2].

\section{Survival benefit in perspective}

Both MADIT-II and our observation document improvements in overall survival which may reach about $31 \%$ such as in MADIT-II [7]. This is also compatible with SCD-HeFT, which reported a risk reduction of $23 \%$ (HR

Table 4 Clinical characteristics of patients in the MADIT II trial

\begin{tabular}{|c|c|c|}
\hline & MADIT II ICD + & MADIT II ICD - \\
\hline & $(n=742)$ & $(n=490)$ \\
\hline & \multicolumn{2}{|c|}{$\begin{array}{l}\text { Prior myocardial infarction more than } \\
28 \text { days ago and an } E F \leq 30 \%\end{array}$} \\
\hline Age (years) & $64 \pm 10$ & $65 \pm 10$ \\
\hline Female Gender (\%) & 16 & 15 \\
\hline LVEF $(\% \pm S D)$ & $23 \pm 5$ & $23 \pm 6$ \\
\hline \multicolumn{3}{|l|}{ Pharmacotherapy } \\
\hline Betablockers (\%) & 70 & 70 \\
\hline ACE inhibitors & 68 & 72 \\
\hline Antiarrhythmics & 16 & 14 \\
\hline Diuretic & 72 & 81 \\
\hline Statins & 67 & 64 \\
\hline Mean follow-up & \multicolumn{2}{|c|}{20 months } \\
\hline Total mortality & 14.2 & 19.8 \\
\hline HR Total mortality & \multicolumn{2}{|c|}{ HR $0.69(95 \% C l 0.51-0.93) ; p=0.016$} \\
\hline $\begin{array}{l}\text { Heart failure related } \\
\text { hospitalization }\end{array}$ & 19.9 & 14.9 \\
\hline
\end{tabular}

Legend: $\mathrm{HR}$, hazard ratio; $\mathrm{Cl}$, confidence interval, $\mathrm{EF}$, ejection fraction; LV, left ventricular.
$0.77 ; \mathrm{p}=0.007)$ and an absolute decrease in mortality of $7.2 \%$ after five years in the overall population. Patients in SCD-HeFT were included based on NYHA class II or III heart failure and a LVEF $\leq 35 \%$ and followed for a median of 45.5 months. In comparison MADIT reported a risk reduction of $54 \%$ for patients with prior MI, and LVEF $\leq$ $35 \%$ (absolute risk 38.6 vs. 15.8\%) and a documented episode of asymptomatic unsustained ventricular tachycardia; and inducible, non suppressible ventricular tachyarrhythmia on electrophysiologic study [11]. Against this background the risk reduction of $48 \%$ in our cohort appears high. This might have been due to confounders that we were not able to fully account for. For example there were more patients with triple vessel disease in the control compared to the ICD group (60.1 vs. 44.3\%; $\mathrm{p}=0.006$ ).

The difference to our data on those of MADIT II is reasonable given that patients with previous proof of arrhythmia were specifically included. None of the patients in the ICD group and $9.8 \%$ of the control group died of primary arrhythmia which illustrates a stronger risk reduction for arrhythmic death. Data are however hard to compare due to substantial differences in antiarrhythmic drug use. For example MUST reported a reduced 5 year rate of cardiac arrest or arrhythmic death by $27 \%$ (HR 0.73) among patients with CAD, a LVEF $\leq 40 \%$ and asymptomatic, not sustained ventricular tachycardia [16].

\section{Heart failure and inappropriate shocks}

An increased risk for heart failure was documented in our observation and also in the MADIT-II trial (Tables 1 and 4). Recently an analysis of risk factors for recurrent heart failure in the MADIT-II trial was published [17]: Risk factors for a first HF hospitalization included treatment with an ICD (HR 1.31; p =0.05), NYHA class $>$ II (HR 1.95; $\mathrm{p}<0.001)$, female gender (HR 1.38; $\mathrm{p}=0.05)$, atrial fibrillation (HR 1.90; $\mathrm{p}=0.001), \mathrm{QRS}>120 \mathrm{~ms}(\mathrm{HR}$ $1.41 ; \mathrm{p}=0.01$ ), diabetes mellitus (HR 1.51; $\mathrm{p}=0.003$ ), heart rate $\geq 80$ (HR 1.35; $\mathrm{p}=0.04$ ), diuretic therapy (HR 1.82; $\mathrm{p}<0.001$ ), and the presence of prerenal azotemia (blood urea nitrogen:creatinine $>20$; HR 1.45; $\mathrm{p}=0.01$ ). The occurrence of one HF event after enrolment was associated with a 2.8 -fold $(\mathrm{p}<0.001)$ increase in the risk of death, whereas after the occurrence of a second event there was a 6.7 -fold $(p<0.001)$ increase in the risk of subsequent mortality.

Inappropriate shocks (those not due to ventricular fibrillation) were also more frequent in patients dying within the observational period (although not significant). This has been associated to the presence of atrial fibrillation (odds ratio 6.2) in a recent analysis of 549 patients with heart failure and ICDs [18]. In a Chinese single center study documenting 34 patients between 
2005 and 2009 reasons for inappropriate ICD discharge were documented [19]. They found these to be again related mainly to supraventricular tachyarrhythmias, especially atrial fibrillation. We were however not able to verify this association because of the low number of cases in our observation.

\section{Limitations}

These data reproduce those found in prior randomized controlled trials. Although this is encouraging a number of limitations have to be acknowledged in addition to the ones mentioned before: 1) This was a retrospective study with all limitations inherent in such designs such as: significant bias that may affect the assignment to the treated group or the control group, incompleteness of data which were not fully captured to answer the question under investigation, difficulty in assessing a temporal or even causal relationship, reliance on the quality of data available with no possibility of verification. 2) The set of data obtained for the patients under investigation was limited so that data interfering with the outcome such those on renal function, biomarkers or the presence of atrial fibrillation were not considered in the analysis. 3) We were not able to report on different causes of death (such as arrhythmic) and only report overall survival. 4) Third the study is small allowing no detailed analyses and multiple adjustments due to limited power. 5) There is a slight imbalance in the degree of heart failure, age and the number of vessels diseased which may not have been adequately accounted for. 6) We obtained no reasons why one group was offered an ICD and the other group not thought both had an indication for ICD use.

\section{Conclusions}

Appreciating the potential limitations of retrospective studies we found that, in patients with ischemic heart disease and left ventricular dysfunction, typical for those in the community setting, ICD use was associated with an improved survival. The benefits were however offset by heart failure and inappropriate shocks which may justify the further research into more advanced devices such as biventricular pacemakers.

\section{Competing interests}

None of the authors reports a conflict of interest with respect to the topic of the present manuscript.

\section{Author contributions}

$\mathrm{TA}, \mathrm{PB}$ and $\mathrm{AC}$ were responsible for the conception and design of the registry, RF for the statistical analysis. PB drafted the manuscript. JB, SH, CZ and UT revised the manuscript for important intellectual content. All authors read and approved the final manuscript.

\section{Availability of supporting data}

None.

\section{Acknowledgements}

None

\section{Author details}

${ }^{1}$ Department I - Cardiology, Angiology, Intensive Care Medicine, Klinikum Lippe-Detmold, Röntgenstrasse 18, 32756, Detmold, Germany. ${ }^{2}$ Institut für Pharmakologie und präventive Medizin, Mahlow, Germany. ${ }^{3}$ Department of Biometry and Medical Statistics, University of Bonn, Bonn, Germany.

${ }^{4}$ Abteilung für Kardiologie, Asklepios Klinik St-Georg, Hamburg, Germany.

Received: 19 January 2012 Accepted: 27 July 2012

Published: 27 July 2012

\section{References}

1. Huikuri HV, Castellanos A, Myerburg RJ: Sudden death due to cardiac arrhythmias. N Engl J Med 2001, 345:1473-1482.

2. Bramlage $P$, Messer $C$, Bitterlich N, Pohlmann C, Cuneo A, Stammwitz E, Tebbenjohanns J, Gohlke H, Senges J, Tebbe U: The effect of optimal medical therapy on 1-year mortality after acute myocardial infarction. Heart 2010, 96:604-609.

3. Echt DS, Liebson PR, Mitchell LB, Peters RW, Obias-Manno D, Barker AH, Arensberg D, Baker A, Friedman L, Greene HL, et al: Mortality and morbidity in patients receiving encainide, flecainide, or placebo. The Cardiac Arrhythmia Suppression Trial. N Engl J Med 1991, 324:781-788.

4. Cairns JA, Connolly SJ, Roberts R, Gent M: Randomised trial of outcome after myocardial infarction in patients with frequent or repetitive ventricular premature depolarisations: CAMIAT. Canadian Amiodarone Myocardial Infarction Arrhythmia Trial Investigators. Lancet 1997, 349:675-682.

5. Julian DG, Camm AJ, Frangin G, Janse MJ, Munoz A, Schwartz PJ, Simon P: Randomised trial of effect of amiodarone on mortality in patients with left-ventricular dysfunction after recent myocardial infarction: EMIAT. European Myocardial Infarct Amiodarone Trial Investigators. Lancet 1997, 349:667-674.

6. Singh SN, Fletcher RD, Fisher SG, Singh BN, Lewis HD, Deedwania PC, Massie BM, Colling C, Lazzeri D: Amiodarone in patients with congestive heart failure and asymptomatic ventricular arrhythmia. Survival Trial of Antiarrhythmic Therapy in Congestive Heart Failure. N Engl J Med 1995, 333:77-82.

7. Moss AJ, Zareba W, Hall WJ, Klein H, Wilber DJ, Cannom DS, Daubert JP, Higgins SL, Brown MW, Andrews ML: Prophylactic implantation of a defibrillator in patients with myocardial infarction and reduced ejection fraction. N Engl J Med 2002, 346:877-883.

8. Hohnloser SH, Kuck KH, Dorian P, Roberts RS, Hampton JR, Hatala R, Fain E, Gent M, Connolly SJ: Prophylactic use of an implantable cardioverterdefibrillator after acute myocardial infarction. N Engl J Med 2004, 351:2481-2488.

9. Zipes DP, Camm AJ, Borggrefe M, Buxton AE, Chaitman B, Fromer M, Gregoratos G, Klein G, Moss AJ, Myerburg RJ, Priori SG, Quinones MA, Roden DM, Silka MJ, Tracy C, Smith SC Jr, Jacobs AK, Adams CD, Antman EM, Anderson JL, Hunt SA, Halperin JL, Nishimura R, Ornato JP, Page RL, Riegel B, Blanc JJ, Budaj A, Dean V, et al: ACC/AHA/ESC 2006 guidelines for management of patients with ventricular arrhythmias and the prevention of sudden cardiac death: a report of the American College of Cardiology/American Heart Association Task Force and the European Society of Cardiology Committee for Practice Guidelines (Writing Committee to Develop Guidelines for Management of Patients With Ventricular Arrhythmias and the Prevention of Sudden Cardiac Death). J Am Coll Cardiol 2006, 48:e247-e346.

10. Chan PS, Chow T, Kereiakes D, Schloss EJ, Waller T, Eagle K, Hayward RA, Vijan S: Effectiveness of implantable cardioverter-defibrillators in patients with ischemic heart disease and left ventricular dysfunction. Arch Intern Med 2006, 166:2228-2233.

11. Moss AJ, Hall WJ, Cannom DS, Daubert JP, Higgins SL, Klein H, Levine JH, Saksena S, Waldo AL, Wilber D, Brown MW, Heo M: Improved survival with an implanted defibrillator in patients with coronary disease at high risk for ventricular arrhythmia. Multicenter Automatic Defibrillator Implantation Trial Investigators. N Engl J Med 1996, 335:1933-1940.

12. Moss AJ, Fadl Y, Zareba W, Cannom DS, Hall WJ: Survival benefit with an implanted defibrillator in relation to mortality risk in chronic coronary heart disease. Am J Cardiol 2001, 88:516-520. 
13. Cygankiewicz I, Gillespie J, Zareba W, Brown MW, Goldenberg I, Klein H, McNitt S, Polonsky S, Andrews M, Dwyer EM, Hall WJ, Moss AJ: Predictors of long-term mortality in Multicenter Automatic Defibrillator Implantation Trial II (MADIT II) patients with implantable cardioverter-defibrillators. Hear Rhythm 2009, 6:468-473.

14. Bardy GH, Lee KL, Mark DB, Poole JE, Packer DL, Boineau R, Domanski M, Troutman C, Anderson J, Johnson G, McNulty SE, Clapp-Channing N, Davidson-Ray LD, Fraulo ES, Fishbein DP, Luceri RM, Ip JH: Amiodarone or an implantable cardioverter-defibrillator for congestive heart failure. $N$ Engl J Med 2005, 352:225-237.

15. Steinbeck G, Andresen D, Seidl K, Brachmann J, Hoffmann E, Wojciechowski D, Kornacewicz-Jach Z, Sredniawa B, Lupkovics G, Hofgartner F, Lubinski A, Rosenqvist M, Habets A, Wegscheider K, Senges J: Defibrillator implantation early after myocardial infarction. N Engl J Med 2009, 361:1427-1436.

16. Buxton AE, Lee KL, Fisher JD, Josephson ME, Prystowsky EN, Hafley G: A randomized study of the prevention of sudden death in patients with coronary artery disease. Multicenter Unsustained Tachycardia Trial Investigators. N Engl J Med 1999, 341:1882-1890.

17. Sze E, Moss AJ, McNitt S, Barsheshet A, Andrews ML, Zareba W, Goldenberg I: Risk Factors for Recurrent Heart Failure Events in the Multicenter Automatic Defibrillator Implantation Trial II (MADIT-II). J Cardiovasc Electrophysiol 2010, 21:1217-1223.

18. Desai H, Aronow WS, Ahn C, Gandhi K, Hussain S, Lai HM, Sharma M, Frishman WH, Cohen M, Sorbera C: Risk factors for appropriate cardioverter-defibrillator shocks, inappropriate cardioverter-defibrillator shocks, and time to mortality in 549 patients with heart failure. Am J Cardiol 2010, 105:1336-1338.

19. Chen TB, Cheng KA, Gao P, Cheng ZW, Fan JB, Jiang XC, Fang Q: Primary prevention of sudden cardiac death by implantable cardioverterdefibrillator therapy in Chinese patients with heart failure: a single-center experience. Chin Med J (Engl) 2010, 123:848-851.

doi:10.1186/1756-0500-5-382

Cite this article as: Aschenbrenner et al: Improved survival of patients with coronary artery disease and low ejection fraction with ICD implantation versus conventional therapy in a real world survey. BMC Research Notes 2012 5:382.

\section{Submit your next manuscript to BioMed Central and take full advantage of:}

- Convenient online submission

- Thorough peer review

- No space constraints or color figure charges

- Immediate publication on acceptance

- Inclusion in PubMed, CAS, Scopus and Google Scholar

- Research which is freely available for redistribution 